\title{
Study of Energy Efficiency Benchmarking Parameter Based on Real Passenger Demand and Energy Data of a High-Speed Traction Lift Bank in Hong Kong with Further Simulations
}

\author{
Melvyn L.H. $\mathrm{Ng}^{1}$ and Albert T.P. So ${ }^{2}$ \\ ${ }^{1}$ The University of Hong Kong \\ ${ }^{2}$ Faculty of Engineering, The University of Hong Kong and Faculty of Arts, Science and \\ Technology, The University of Northampton, United Kingdom \\ ${ }^{2}$ Corresponding author's email address: alberttpso@gmail.com,
}

\begin{abstract}
A holistic normalization method was developed, which can simultaneously assess both drive efficiency and traffic control performance on a real-time basis of a lift system, termed $<\mathrm{J} / \mathrm{kg}-\mathrm{m}>$ measured in the unit, $\mathrm{J} / \mathrm{kg} / \mathrm{m}$. Since 2012, it has been adopted by the HKSAR Government as an emerging good engineering practice in the Technical Guidelines of the Building Energy Code. A study of the parameter based on pure simulations using artificial traffic patterns and simple energy patterns was conducted, recommending that a value of $40 \mathrm{~J} / \mathrm{kg} / \mathrm{m}$ could indicate an efficient system. In this article, the study is conducted again based on real passenger demand and real energy profiles on a bank of seven lifts serving a super-high-rise luxurious office building in Hong Kong, with a conclusion that the previous recommendation is still valid, supported by real data. The study includes variation by simulation in traffic control algorithms and the number of lifts of the bank to study the "undersizing effect" with the same passenger demands throughout a typical weekday, from morning to evening.
\end{abstract}

Keywords: Energy consumption, benchmarking parameter, lift traffic, lift drive, normalization, computer simulation

\section{INTRODUCTION}

Since 1995, Hong Kong SAR Government has been promoting energy conservation and efficiency through issuing codes of practice and enforcing mandatory laws. The Code of Practice for Overall Thermal Transfer Value (OTTV) in Buildings (Buildings 1995) was first published by the Buildings Department of the Government in 1995. Then, a task force was set up in 1997 by the Electrical \& Mechanical Services Department (EMSD) to publish codes of practice on four building systems, namely electrical, air-conditioning, lighting, and lifts and escalator installations respectively. These codes aimed at providing the minimum energy efficiency standards in new and retrofitted buildings. Until 2012, all these codes had been adopted by the community on a voluntary basis. The Building Energy Efficiency Ordinance (Cap. 610) came into effect on $21^{\text {st }}$ September, 2012 with an objective to promote the enhancement of energy efficiency in Hong Kong's buildings with statutory regulations. The original codes of practice for the four different building systems were then combined into one volume, called Code of Practice for Energy Efficiency of Building Services Installation (called Building Energy Code or BEC in short). The first BEC was published in 2012 (EMSD 2012a), then revised in 2015 (EMSD 2015a) and 2018 (EMSD 2018a). Every time when it was revised, the requirements were further strengthened or tightened. Together with each revision of the $B E C$, associated technical guidelines were also published (EMSD 2012b, 2015b, 2018b).

In the section on lift and escalator installation in the $B E C$, the maximum power consumption in $\mathrm{kW}$ when a fully loaded traction lift traveling upward under the rated speed is to be limited according to a table using rated capacity, rated speed as classifications. How smart the dispatcher or supervisory controller is has no effect on the assessment by the $B E C$. In other words, lift energy performance is 
only dependent of the drive performance while the supervisory control has no way to contribute.

The second author of this paper, together with other researchers, noticed fifteen years ago (So et al 2005) that merely the existence of an energy efficient motor drive should not be the ultimate solution to an energy efficient lift system. Efficiency of the drive can only account for the hardware performance, whereas another main saving should come from the supervisory traffic control. Based on this consideration, a good benchmarking parameter for energy comparison of lift systems must take care of both the hard physical motor drive performance as well as the soft traffic control algorithms. Therefore, the idea of $\langle\mathrm{J} / \mathrm{kg}-\mathrm{m}>$, with a unit in $\mathrm{J} / \mathrm{kg} / \mathrm{m}$, was proposed.

Since 2012, this benchmarking parameter has been included in the technical guidelines of the $B E C$ (EMSD 2012b, 2015b, 2018b) as an emerging good engineering practice for normalization and monitoring of lift energy consumption. By definition, it is the average energy to convey one unit of mass, either passengers or goods in $\mathrm{kg}$, to travel a distance of one metre, irrespective of direction or speed over a fixed and agreed period of time, say one hour, two hours or even a day. In simple physics, it is an overall term of efficiency, "J" representing the input (energy) to the lift system and "kg-m" representing the output (how many passengers can be handled and how far they can go) of the lift system. Obviously, $<\mathrm{J} / \mathrm{kg}-\mathrm{m}>$ should be as low as possible. There are two ways to improve or lower its value. An energy efficient motor drive can of course lower such average value by reducing the numerator of the ratio, while an energy efficient traffic control system can lower such average value by increasing the denominator of the ratio. The latter is achieved by handling more passengers in one trip. Of course, the average waiting time $(A W T)$ and average transit time $(A T T)$ of passengers must be limited for satisfactory traffic performance. In other words, by using $<\mathrm{J} / \mathrm{kg}-\mathrm{m}>$, it is worth to spend a bit more energy to convey more passengers during every trip. Here, a trip is defined as a brake-tobrake journey commencing at the instant when the brake is released to the instant when the brake is applied again.

Without loss of generality, this definition, explained here again for easy reference, also applies to a bank of lift cars. A fixed time window, $T$, usually set at 2 hours $=7,200$ seconds, is used to assess a individual lift or a bank of lifts. A time increment, $\Delta T$, say 15 minutes long $=900$ seconds, can be defined so that the first window from 0 to $T$, and another time window from $\Delta T$ to $T+\Delta T$ can be formulated, one after one. At the same time, the total energy, $E_{T}(k)$ of either one lift or a bank of lifts, consumed during the $k$ th time window of $T$ seconds long has to be recorded. $E_{T}(k)$ includes not just the consumption of the motor drive but others including lighting, ventilation, control and indication etc. Eventually, one value, $<\mathrm{J} / \mathrm{kg}-\mathrm{m}>(k)$, can be estimated for the $k$ th time window. A daily or weekly average can finally be obtained. For the $k$ th time window, the following equation (1) is valid. Any brake-to-brake journey (car load, $w_{i}(k)$, and distance traveled, $d_{i}(k)$, for the $i$ th journey) either within the $k$ th time window or across the two borders of the $k$ th window could also be included in equation (1) as it does not affect the statistics by much. It is assumed that there are $N$ number of brake-to-brake journeys within the $k$ th window.

$$
<\mathrm{J} / \mathrm{kg}-\mathrm{m}>(k)=\frac{E_{T}(k)}{\sum_{i=1}^{N} w_{i}(k) d_{i}(k)}
$$

Such parameter was also employed to develop a statistically energy saving scheme by varying the counterweight setting of a lift from time to time, say every two weeks when the lift is regularly serviced in Hong Kong (So et al 2012). 
To evaluate $<\mathrm{J} / \mathrm{kg}-\mathrm{m}>$ on a real time basis, four measurements are to be made instantaneously and continuously during operation:

i) energy consumed, in Joules, over the fixed period of time, $T$, say 7,200 seconds $=2$ hours long;

ii) mass of load, in kilograms, inside the lift car, at any time within $T$;

iii) position of the lift car, in metres above the lowest floor, along the hoistway at any time within $T$; this is to estimate the distance traveled by the lift car; and

iv) the status of the brake because a brake-to-brake journey is always considered.

Data (i) above is readily available at all new lifts in Hong Kong because the installation of a power meter is mandatorily required in the $B E C$ 2018. Unfortunately, data (ii), (iii) and (iv) are usually unavailable with most existing lifts in Hong Kong. Even though an advanced computerized lift controller possesses such information intrinsically, lift maintenance contractors are usually unable or reluctant to disclose the proprietary protocol for the $<\mathrm{J} / \mathrm{kg}-\mathrm{m}>$ monitor to retrieve necessary real time data. Before a simple added-on kit is invented and made popular to be implemented on different brands and models of lifts to gather necessary raw data, simulation has to be relied on to determine an appropriate threshold value of such benchmarking parameter for comparing the energy performance of different lifts. Such a reliable threshold value is important if $\langle\mathrm{J} / \mathrm{kg}-\mathrm{m}>$ has to be enforced in the $B E C$.

A study based on pure simulation using artificial passenger demands and simple energy templates was conducted (So et al 2018) with the following observations and suggestions:

i) $\quad \quad \mathrm{J} / \mathrm{kg}-\mathrm{m}>$ tends to be higher during the transition between up-peak and lunch-peak traffic, and gets lower during down-peak traffic.

ii) $\quad<\mathrm{J} / \mathrm{kg}-\mathrm{m}>$ tends to be much lower for drives with re-generative braking facility even of the same traffic control, thus proving that re-generative braking is necessary for all modern energy efficient systems.

iii) Zoning, the use of computer based intelligent traffic control, and modern lift drives can give a better performance.

iv) Overdesign in terms of number of lift cars within a bank could give a slightly poorer performance.

v) An average value of $50 \mathrm{~J} / \mathrm{kg} / \mathrm{m}$ could easily be met by modern drives while a good value for reference could be $40 \mathrm{~J} / \mathrm{kg} / \mathrm{m}$ or below. This is based on a $T=7,200$ seconds with a moving window incremented by 900 seconds. And it is applicable to a bank of lifts with a modern dispatcher.

\section{THE REAL LIFT SYSTEM}

\subsection{The Lift Bank under Study}

A super-high-rise office building located at the central business district of Hong Kong was chosen. A bank of seven lifts serves a mid-rise zone of the building, at ground floor and then $20 / \mathrm{F}, 21 / \mathrm{F}, \ldots . ., 34 / \mathrm{F}$ until $35 / \mathrm{F}$. The height of $20 / \mathrm{F}$ is $65 \mathrm{~m}$ above the ground floor while that of $35 / \mathrm{F}$ is $115 \mathrm{~m}$ above the ground floor. Floor height is varying, floor by floor. Technical specifications of the seven identical lifts are shown in Table 1. 
Table 1 Technical specifications of the 7 identical lifts under study

\begin{tabular}{|l|l|l|l||l|l|}
\hline Item & Value & Item & Value & Item & Value \\
\hline \hline Rated capacity & $1,590 \mathrm{~kg}$ & Door pre-opening time & $1 \mathrm{~s}$ & Door opening time & $1.5 \mathrm{~s}$ \\
\hline Door closing time & $2.5 \mathrm{~s}$ & $\begin{array}{l}\text { Dwell time 1 (before last } \\
\text { entering passenger) }\end{array}$ & $3 \mathrm{~s}$ & $\begin{array}{l}\text { Dwell time 2 (after last } \\
\text { entering passenger) }\end{array}$ & $2 \mathrm{~s}$ \\
\hline Rated speed & $5 \mathrm{~m} / \mathrm{s}$ & $\begin{array}{l}\text { Acceleration/deceleration } \\
\text { rate }\end{array}$ & $\begin{array}{l}0.8 \\
\mathrm{~m} / \mathrm{s}^{2}\end{array}$ & Jerk & $\begin{array}{l}0.8 \\
\mathrm{~m} / \mathrm{s}^{3}\end{array}$ \\
\hline Start delay loading & $1.5 \mathrm{~s}$ & Leveling delay & $0 \mathrm{~s}$ & & $75 \mathrm{sg}$ \\
\hline $\begin{array}{l}\text { Passenger } \\
\text { time }\end{array}$ & Passenger unloading time & $1.0 \mathrm{~s}$ & Passenger mass & \\
\hline $\begin{array}{l}\text { Capacity factor by } \\
\text { mass }\end{array}$ & $80 \%$ & & & \\
\hline
\end{tabular}

\subsection{Assessment of Lifts based on $B E C 2018$}

The aims of $B E C$ related to lifts are to reduce power consumption through imposing maximum allowable electrical power of motor drive, the provision of regenerative braking, and the reduction in losses in the utilization of power. Table 2 shows the compliance of the seven identical lifts of the bank with the $B E C$. 
Table 2 Assessment of lifts based on BEC 2018

\begin{tabular}{|c|c|c|}
\hline & $\begin{array}{l}\text { Requirements } \\
\text { according to } B E C\end{array}$ & $\begin{array}{l}\text { Performance of } \\
\text { every lift }\end{array}$ \\
\hline Lift type & & Traction \\
\hline Clause number and prescription & Requirement & Fulfillment \\
\hline $\begin{array}{l}8.4 .1 .1 \\
\text { Running active electrical power of the motor drive } \\
\text { of a traction drive lift carrying a rated load at its } \\
\text { rated speed in an upward direction }\end{array}$ & $\begin{array}{l}\text { limited to } 56 \mathrm{~kW} \\
\text { based on Table } \\
8.4 .1 \mathrm{~b} \text { for an } \\
\text { existing building }\end{array}$ & $<53.2 \mathrm{~kW}$ \\
\hline $\begin{array}{l}8.5 .1 .1 \\
\text { Power factor when the lift is carrying a rated load at } \\
\text { its rated speed and traveling in an upward direction }\end{array}$ & at least 0.85 & $>0.85$ \\
\hline $\begin{array}{l}\text { 8.5.2 } \\
\text { Maximum Lift Decoration Load }\end{array}$ & $\begin{array}{l}\text { limited to } 490 \mathrm{~kg} \\
\text { based on Table 8.5.2 }\end{array}$ & $<490 \mathrm{~kg}$ \\
\hline $\begin{array}{l}8.5 .3 \\
\text { Under normal operating status, at least one lift of a } \\
\text { lift bank should operate under a parking mode } \\
\text { during low traffic period when the traffic demand on } \\
\text { the vertical transportation system is low. Under a } \\
\text { parking mode of operation, a lift should not respond } \\
\text { to passenger calls until it returns to the normal } \\
\text { operation mode }\end{array}$ & & $\begin{array}{l}\text { Lift under parking } \\
\text { mode when traffic is } \\
\text { low and no } \\
\text { passenger call. The } \\
\text { lift under parking } \\
\text { mode does not } \\
\text { respond to landing } \\
\text { calls until traffic gets } \\
\text { high }\end{array}$ \\
\hline $\begin{array}{l}8.5 .4 .1 \\
\text { Ventilation of a lift car after idling for } 2 \text { minutes } \\
\text { should be shut off automatically until the lift is } \\
\text { activated again by passenger call }\end{array}$ & & Complied \\
\hline $\begin{array}{l}8.5 .4 .2 \\
\text { Air-conditioning of a lift car }\end{array}$ & & $\begin{array}{l}\text { No air conditioner } \\
\text { on car top }\end{array}$ \\
\hline $\begin{array}{l}\text { 8.5.4.3 } \\
\text { Power consumption of the lift car ventilation fan }\end{array}$ & $\begin{array}{l}\text { limited to } 0.7 \mathrm{~W} \text { per } \\
\text { litre per second }\end{array}$ & Complied \\
\hline $\begin{array}{l}8.6 .1 \\
\text { Maximum Total Harmonic Distortion of motor drive } \\
\text { of lifts }\end{array}$ & $\begin{array}{l}\text { limited to } 35 \% \\
\text { based on Table } 8.6 .1\end{array}$ & Complied \\
\hline $\begin{array}{l}8.7 \\
\text { Metering and monitoring facilities }\end{array}$ & & $\begin{array}{l}\text { Metering devices } \\
\text { installed }\end{array}$ \\
\hline
\end{tabular}

Based on Table 2, it can be concluded that all seven lifts of this bank are considered energy efficient with respect to the statutory regulations of Hong Kong. 


\subsection{Passenger Demand}

The real lift bank is operated under an ACA (automatic car allocation) mode of control where passengers need to register their individual destination floor at the ground floor and are directed to the pre-selected car by the dispatcher. All passenger demands on a typical weekday of the office building are recorded from 7:30 am to $8: 30 \mathrm{pm}$. This long period includes different traffic patterns from morning up-peak, interfloor, lunch peak, interfloor, to evening down-peak. Table 3 shows a portion (a few landing calls in the beginning of the day) of the passenger demand which indicates what raw data is to be inputted to the simulation software, Elevate ${ }^{\mathrm{TM}}$.

Table 3 Passenger Demand on a typical Working Day

\begin{tabular}{|l|l|l|l|l|}
\hline Time (s) & $\begin{array}{l}\text { Origin } \\
\text { floor (/F) }\end{array}$ & $\begin{array}{l}\text { Destination } \\
\text { floor (/F) }\end{array}$ & $\begin{array}{l}\text { Weight of } \\
\text { passenger (kg) }\end{array}$ & Explanation \\
\hline \hline 27001 & 5 & 9 & 75 & $\begin{array}{l}\text { At 7:30:01 am, one passenger with a weight of 75 } \mathrm{kg} \text { wants } \\
\text { to travel from 23/F to 27/F }\end{array}$ \\
\hline 27034 & 10 & 15 & 75 & $\begin{array}{l}\text { At 7:30:34 am, one passenger with a weight of } 75 \mathrm{~kg} \text { wants } \\
\text { to travel from 28/F to 33/F }\end{array}$ \\
\hline 27060 & 1 & 4 & 75 & $\begin{array}{l}\text { At 7:31:00 am, one passenger with a weight of } 75 \mathrm{~kg} \text { wants } \\
\text { to travel from G/F to 22/F }\end{array}$ \\
\hline 27130 & 1 & 6 & 75 & $\begin{array}{l}\text { At 7:32:10 am, one passenger with a weight of } 75 \mathrm{~kg} \text { wants } \\
\text { to travel from G/F to 24/F }\end{array}$ \\
\hline
\end{tabular}

Since the ACA controller assumes that every passenger needs to register his/her own destination, each passenger demand record belongs to a single passenger. Although these seven lifts serve a mid-rise zone, floor numbers are sequentially inputted to the simulation software, starting from $0 / \mathrm{F}$ meaning G/F, to $1 / F$ meaning $20 / F$, and so on.

\subsection{Energy Template}

Section 2.3 above shows that the passenger demand was real, belonging to what happened on a typical working day. Next, the energy template is to be considered. For each brake-to-brake journey, the total energy consumed in Joules has to be estimated so that $E_{T}$ can be calculated by summing all of them. Obviously, energy consumption depends on the car load, direction of travel and distance traveled. If the car is traveling upward, less energy is consumed with less load, and vice versa; if the car is traveling downward, less energy is consumed with more load, and vice versa. Regarding distance traveled, it is known that energy is consumed more during the acceleration stage. If the journey is short, energy consumed per unit load and per unit distance tends to be higher, and vice versa. Therefore, a full multidimensional matrix is needed where energy consumed per brake-to-brake journey is related to car load, direction of travel, and the origin/destination floors.

Such matrix, in principle, has infinite number of entries as there are two directions of travel, total number of types being equal to ${ }_{17} P_{2}=272$, as there are totally seventeen number of floors served by the bank, including the ground floor, and varying car load from $0 \%$ to $100 \%$. Since the counterweight was adjusted to $50 \%$ of rated load, it is good enough to prepare the energy matrix for a car load from $0 \%$ to $50 \%$ only due to symmetry. Hence, the exact energy consumed by a limited number of such combinations was measured on site while others were evaluated by interpolation. A part of the resultant matrix is shown in Figure 1 while the full energy profile is shown by a 3-dimensional surface in Figure 2. It should be noted that such energy consumption included that of lighting, ventilation and indication during the journey but did not include those consumed during a stop. 
The leftmost column shows the distance traveled in metres, a minus sign indicating that the lift car is traveling downward between two floors, and vice versa. The upmost row shows the car load in percentage of the rated capacity. This figure only shows selected rows and columns due to the size of the matrix. The energy is measured in Joules. It can be seen that when the car is almost vacant and traveling down, it consumes huge amount of energy because the drive is basically lifting the counterweight upward. When an almost empty car is traveling upward, the energy consumed is negative, meaning that the regenerative braking device is functioning.

\begin{tabular}{|c|c|c|c|c|c|c|c|c|c|}
\hline \multirow{2}{*}{\multicolumn{2}{|c|}{ Power (J) ע }} & \multicolumn{8}{|l|}{ Load (\%) $\rightarrow$} \\
\hline & & 0 & 1 & 2 & 3 & 4 & 5 & 6 & 7 \\
\hline Distance & -102 & 11204.79 & 10881.40 & 10623.60 & 10395.20 & 10197.66 & 10019.62 & 9854.42 & 9693.64 \\
\hline \multirow[t]{14}{*}{$(\mathrm{m}) \downarrow$} & -99 & 10830.12 & 10490.90 & 10233.74 & 10023.90 & 9836.53 & 9666.01 & 9505.94 & 9352.13 \\
\hline & -96 & 10455.92 & 10076.42 & 9821.51 & 9640.24 & 9461.02 & 9311.28 & 9160.99 & 9010.22 \\
\hline & -93 & 10082.19 & 9560.61 & 9453.57 & 9310.65 & 9154.03 & 8992.77 & 8834.25 & 8677.92 \\
\hline & -90 & 9709.42 & 9481.81 & 9279.67 & 9089.14 & 8904.05 & 8722.65 & 8544.41 & 8372.56 \\
\hline & -3 & 658.47 & 640.78 & 620.61 & 597.60 & 596.04 & 590.28 & 580.30 & 565.90 \\
\hline & 3 & 48.50 & 54.65 & 55.61 & 63.11 & 64.95 & 61.57 & 59.50 & 67.63 \\
\hline & 6 & 25.27 & -95.42 & -83.87 & -63.62 & -66.44 & -66.63 & -65.91 & -65.10 \\
\hline & 9 & 2.16 & -237.50 & -231.12 & -223.01 & -213.99 & -205.53 & -197.62 & -188.49 \\
\hline & 12 & -254.71 & -419.60 & -412.10 & -406.00 & -375.84 & -347.81 & -321.10 & -320.30 \\
\hline & 15 & -511.79 & -586.77 & -571.13 & -553.87 & -534.04 & -508.90 & -497.35 & -484.05 \\
\hline & 18 & -768.67 & -756.43 & -742.99 & -728.90 & -720.66 & -714.20 & -690.11 & -667.52 \\
\hline & 21 & -933.71 & -949.41 & -930.74 & -913.63 & -898.15 & -884.10 & -857.37 & -832.39 \\
\hline & 24 & -1098.69 & -1131.22 & -1085.93 & -1062.48 & -1044.54 & -1023.62 & -1004.17 & -984.47 \\
\hline & 27 & -1263.65 & -1319.62 & -1281.06 & -1208.20 & -1195.54 & -1180.49 & -1163.92 & -1146.04 \\
\hline
\end{tabular}

Figure 1 Part of the Energy Matrix

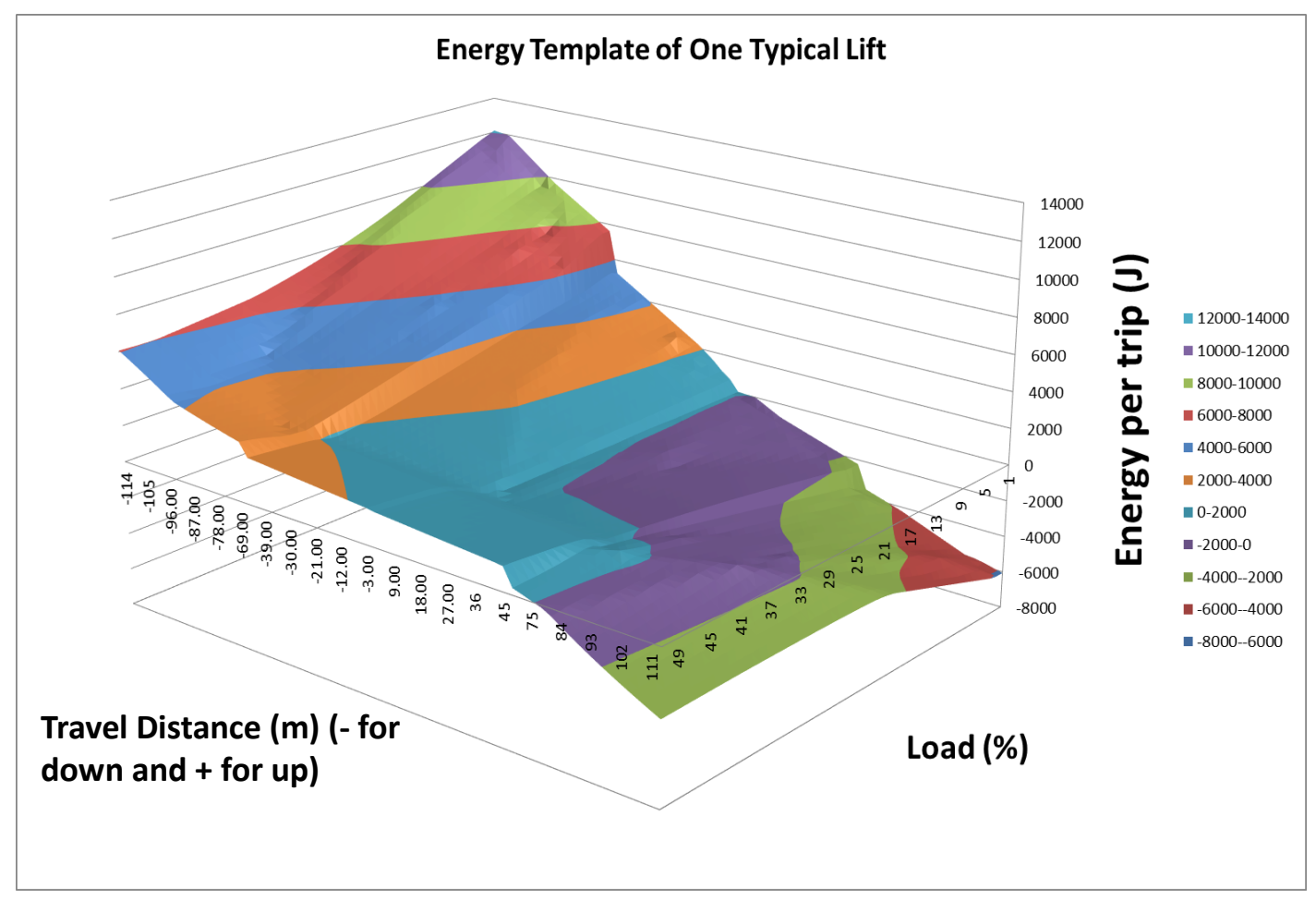

Figure 2 Full Energy Profile of one typical Lift of the Bank 


\section{REAL PASSENGER DEMAND, REAL TRAFFIC HISTORY AND REAL BRAKE-TO- BRAKE-JOURNEY ENERGY PATTERNS (REAL ENERGY PATTERNS HEREINAFTER)}

As mentioned above, the passenger demand throughout a typical working weekday was continuously recorded from 07:30 am to 8:30 pm, shown in Figure 3, a summary of which is shown in Table 4. As seen, the four peaks only account for about $52 \%$ of all calls of the whole day while total number of calls within the period from 7:30 am to 8:30 pm account for about $94 \%$ of all calls of the whole day. At the same time, the traffic history of all seven cars was also recorded in the form very similar to the spatial plot depicted in the simulation report of Elevate ${ }^{\mathrm{TM}}$ as shown in Figure 4. At any instant, the lift number, car load, and position were recorded so that individual brake-to-brake journeys could be identified. The exact amount of energy consumed of each brake-to-brake journey is then estimated based on the energy matrix shown in Figure 1 and Figure 2.

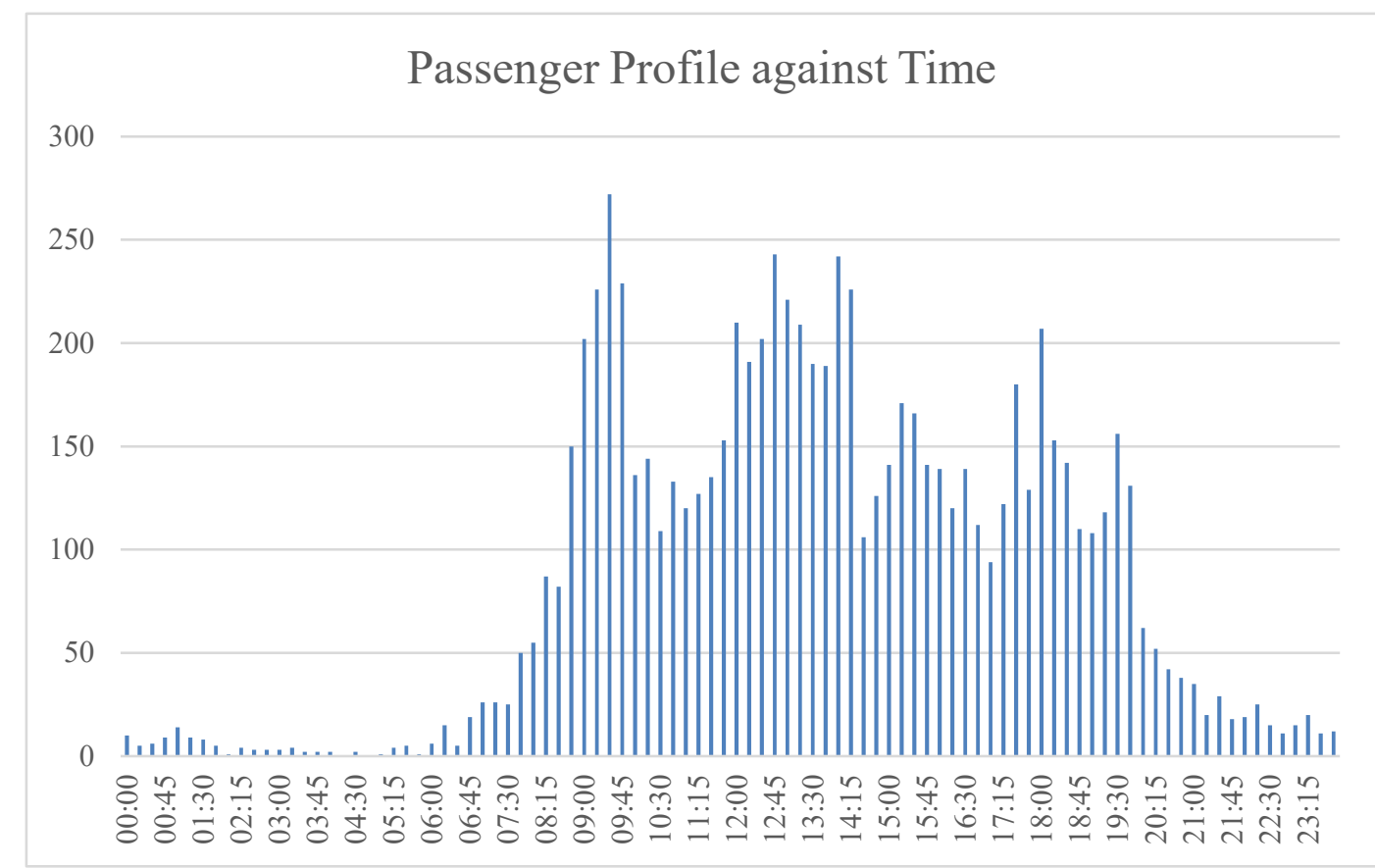

Figure 3 Real Passenger Profile against Time on a Typical Day

Table 4 Measurement window and Number of calls

\begin{tabular}{|l|l|l|l|}
\hline Measuring window & Time & Number of calls & \% of total calls \\
\hline Up peak & $08: 45-10: 15$ & 1215 & $14.8 \%$ \\
\hline Lunch peak & $12: 30-14: 00$ & 1254 & $15.3 \%$ \\
\hline Inter-floor & $15: 00-16: 30$ & 878 & $10.7 \%$ \\
\hline Down peak & $17: 30-19: 00$ & 921 & $11.2 \%$ \\
\hline ¿four peak windows & - & 4268 & $52.1 \%$ \\
\hline Whole day & $07: 30-20: 30$ & 7683 & $93.8 \%$ \\
\hline
\end{tabular}


Here, all seven lifts are considered one system. In other words, equation (1) applies to all brake-tobrake journeys of all seven lifts $(j=1, . ., 7)$ within a time window, $T$ s long, as shown in equation (2). As mentioned before, a time window 7,200 seconds long is used with an increment of 900 seconds. That means, the first window is from 7:30 am to 9:30 am with the centre-point at 8:30 am, the second window from 7:45 am to 9:45 am centered at 8:45 am, ...., and so on, until the last window from 6:30 pm to $8: 30 \mathrm{pm}$ centered at 7:30 pm.

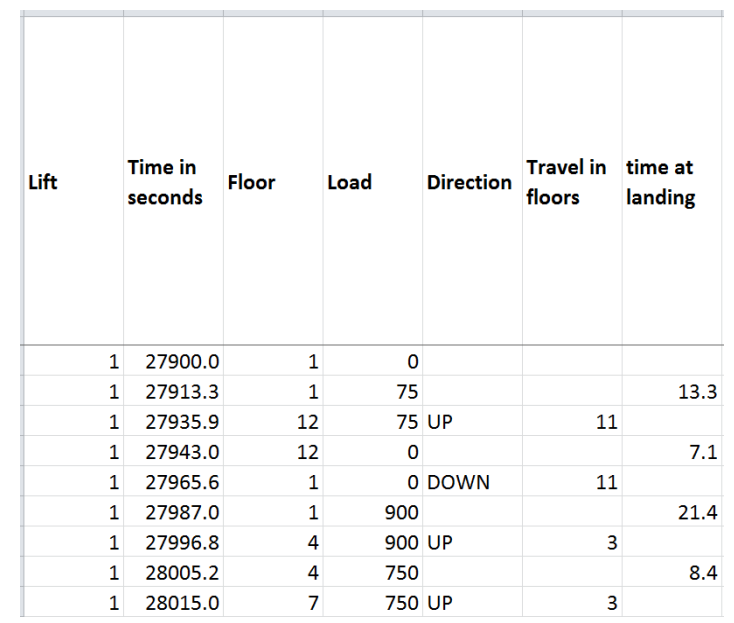

Figure 4 Format of Spatial Plot of Elevate ${ }^{\mathrm{TM}}$ adopted to record real traffic history

$$
<\mathrm{J} / \mathrm{kg}-\mathrm{m}>\text { (all cars) }(k)=\frac{\sum_{j=1}^{7} E_{T j}(k)}{\sum_{j=1}^{7} \sum_{i=1}^{N_{j}(k)} w_{j i}(k) d_{j i}(k)}
$$

$N_{j}(k)$ refers to the number of brake-to-brake journeys of the $j$ th lift within the $k$ th time window. $w_{j i}$ is the $j$ th car load in the $i$ th journey and $d_{j i}$ is the distance traveled by the $j$ th car in the $i$ th journey.

Figure 5(a) shows the $<\mathrm{J} / \mathrm{kg}-\mathrm{m}>$ curve fitted to all 45 centre-points from 8:30 am to 7:30 pm and the average (red horizontal line) of all these 45 values. It can be seen that there are three minima's, at uppeak, lunch-peak and down-peak periods. Maxima's are at the two instants between the minima's, representing the interfloor traffic. The passenger report was generated on a typical working date, which included the information of passenger arrival time, boarding floor and destination. This information was inputted to Elevate ${ }^{\mathrm{TM}}$ to run the traffic simulation.

From the passenger report, the sum of number of calls are counted in each 15 minute interval throughout the whole day. Then, the density of calls in different periods can be counted to conclude the actual time of the measuring time window.

The average value throughout the whole day was $50.77 \mathrm{~J} / \mathrm{kg} / \mathrm{m}$ based on such scenario of real passenger demand, real energy brake-to-brake-journey patterns, real control and real traffic. Such average value was computed by averaging all 45 values from $8: 30$ am to 7:30 pm. Readers are reminded that such bank of lifts is operated by an ACA supervisory controller. 
 PATTERNS}

\subsection{Simulated Traffic Control History - Lift System Originally Sized}

Figure 5(a) shows the real situation except that the energy consumed when a lift car is stationary is not considered. As mentioned before, the real bank of seven lifts is controlled by an ACA system. By using the same passenger demand all day long, the operation of these seven lifts was simulated on Elevate ${ }^{\mathrm{TM}}$ by using different built-in control algorithms inside the software, namely ACA, ETA (estimated time to arrival) and Collective. Then, corresponding spatial plots, such as one shown in Figure 4, were obtained where the energy matrix of Figure 2 was applied to all brake-to-brake journeys and the resultant 45 values of $<\mathrm{J} / \mathrm{kg}-\mathrm{m}>$ were obtained and plotted out with curve fitting, as shown in Figure 5 (b) for ACA ( $\mathrm{sim}$ ) with an average of $25.58 \mathrm{~J} / \mathrm{kg} / \mathrm{m}$ throughout the whole day, Figure 5(c) for ETA(sim) with an average of $25.81 \mathrm{~J} / \mathrm{kg} / \mathrm{m}$ and Figure 5(d) for Collective (sim) with an average of $20.67 \mathrm{~J} / \mathrm{kg} / \mathrm{m}$.

The average value using real traffic history of $50.77 \mathrm{~J} / \mathrm{kg} / \mathrm{m}$ as mentioned in section 3 of this article seems to be exceptionally high as compared with what was simulated in this section, almost doubled. That is due to the fact that this super high-rise building is a very luxurious office building in the central business district of Hong Kong, occupied by many anchored tenants which are internationally reputable. The controller, subject to the desire of the property owner, has been adjusted to limit car load of each lift to $80 \%$, i.e. 17 passengers only. The reason behind is that by rule, each passenger must register at the keypad at the ground floor to indicate his/her destination and be assigned a lift. For each request, the system assumes that a single passenger initiates the landing call while the system limits car assignment to at most 17 headcounts. In real life situation, multiple passengers may have registered only one request. During peak time, some passenger may not be able to get into the assigned lift because it has already been filled up with un-registered passengers. Those rejected passengers need to register new requests and thus the waiting time is dramatically increased. Therefore, a $20 \%$ load buffer is left behind to tackle this situation, and to provide a higher comfort level to passengers during normal situation.

In other words, the lift bank was intentionally over designed. This argument can be shown in a later section of this article that the bank can still perform well if the number of lifts is reduced from seven to five.

By checking Figures 5(b), 5(c) and 5(d), the shape of the three curves looks similar regarding minima's and maxima's. A quick glancing through the four figures reveals that basically, all of them exhibit three minima's and two maxima's at almost the same time of a day. The average values of $<\mathrm{J} / \mathrm{kg}-\mathrm{m}>$ under all three types of traffic control in Elevate ${ }^{\mathrm{TM}}$ fall into a close range of order of magnitudes. However, also revealed in Figures 6 and 7, the average values under ACA and ETA are similar but that under Collective Control is always the champion. It seems that "Collective Control" can always perform exceptionally well under the second half of the lunch-peak and, in particular, the down-peak after office hours. That significantly pulls down the average value of $\langle\mathrm{J} / \mathrm{kg}-\mathrm{m}>$. This is an interesting phenomenon, worthy of receiving further study. 


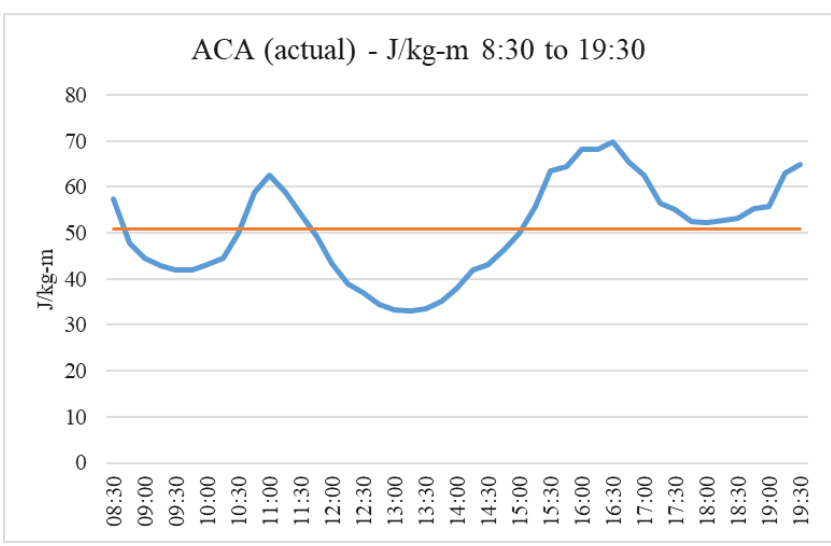

Figure $5(\mathrm{a})<\mathrm{J} / \mathrm{kg}-\mathrm{m}>$ profile of seven lifts based on real demand and real traffic

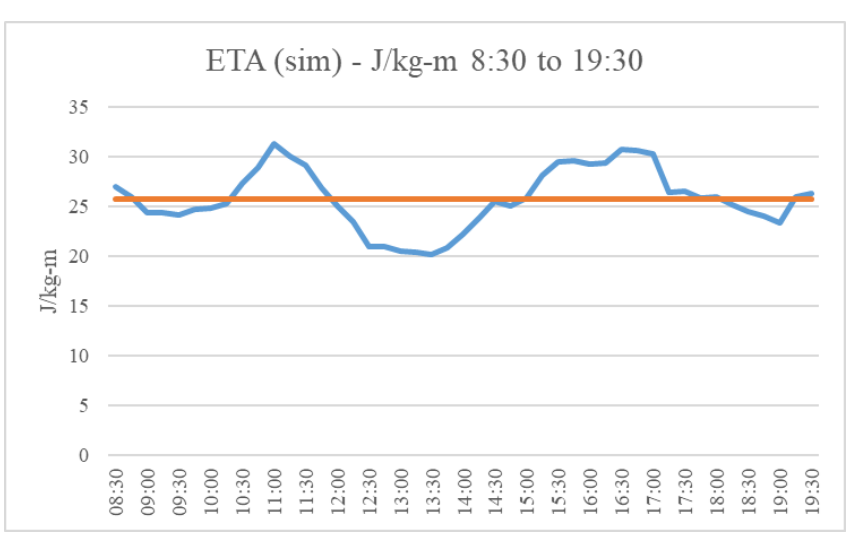

Figure $5(\mathrm{c})<\mathrm{J} / \mathrm{kg}-\mathrm{m}>$ profile of seven lifts based on real demand and simulated ETA

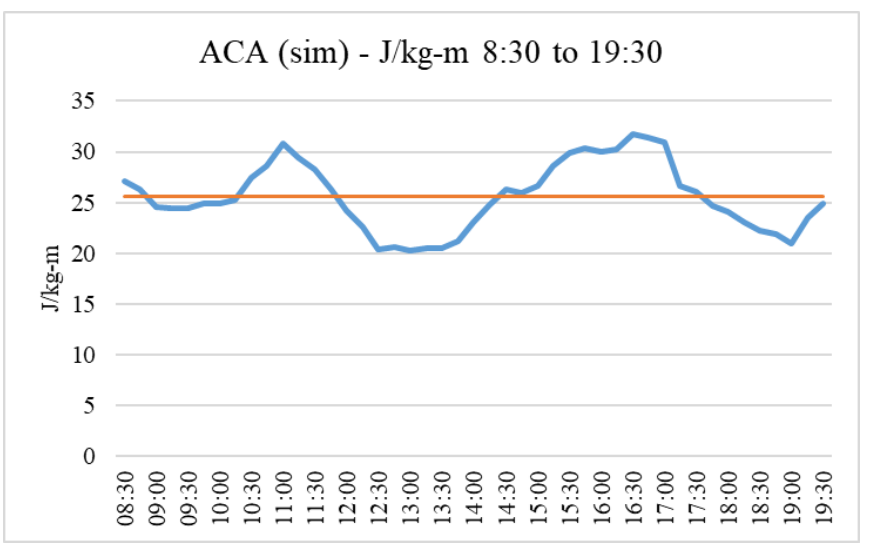

Figure $5(\mathrm{~b})<\mathrm{J} / \mathrm{kg}-\mathrm{m}>$ profile of seven lifts based on real demand and simulated ACA

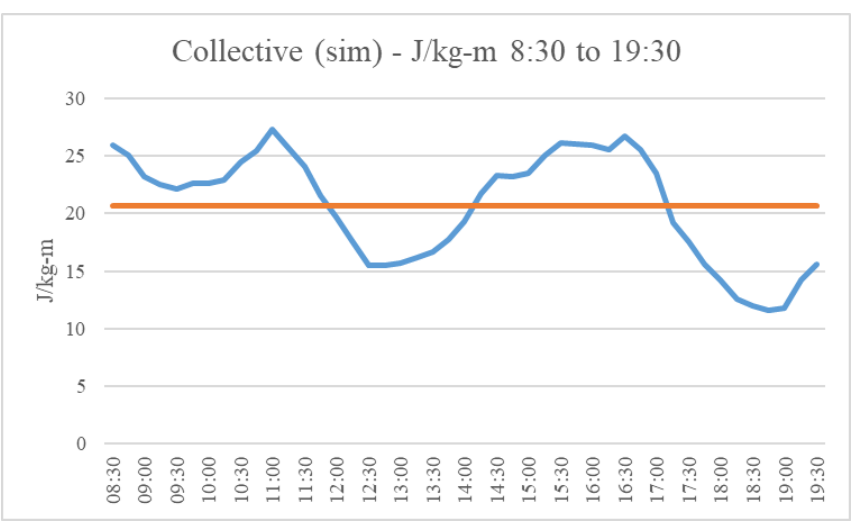

Figure $5(\mathrm{~d})<\mathrm{J} / \mathrm{kg}-\mathrm{m}>$ profile of seven lifts based on real demand and simulated Collective 


\subsection{Simulated Traffic Control History - Lift System Undersized}

Based on the observation in Figures 5(a) to 5(d), the lunch-peak and down-peak periods are obviously minima's. That may point to a fact that $<\mathrm{J} / \mathrm{kg}-\mathrm{m}>$ tends to be lower when most passengers are allowed to fill up the lift car, journey by journey, because the denominator can be increased accordingly. Hence, simulation under three different control algorithms with the same passenger demand throughout the day but with less lift cars, i.e. six and five, was carried out to check the impact on the benchmarking parameter. Figures $6(\mathrm{a}), 6(\mathrm{~b}), 6(\mathrm{c})$ show the $<\mathrm{J} / \mathrm{kg}-\mathrm{m}>$ profiles under ACA, ETA and Collective with six lifts. Figures 7(a), 7(b), 7(c) show the $<\mathrm{J} / \mathrm{kg}-\mathrm{m}>$ profiles under ACA, ETA and Collective with only five lifts.

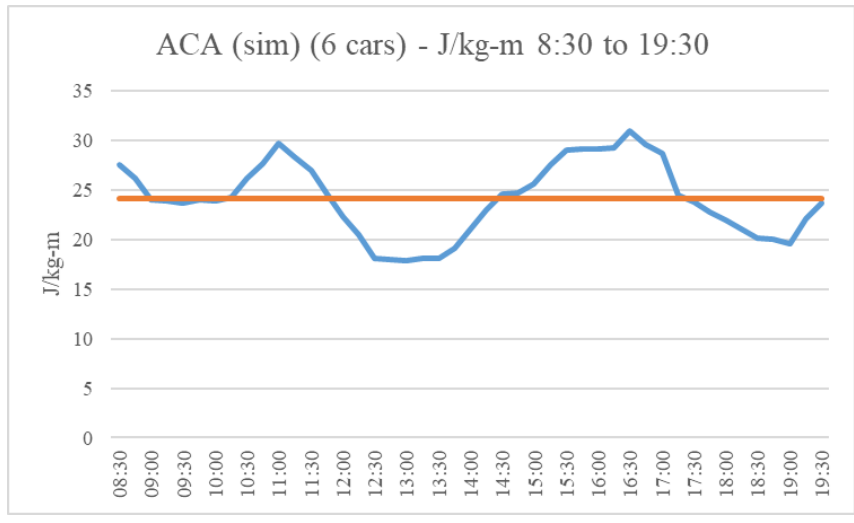

Figure $6(\mathrm{a})<\mathrm{J} / \mathrm{kg}-\mathrm{m}>$ profile of six lifts based on real demand and simulated ACA

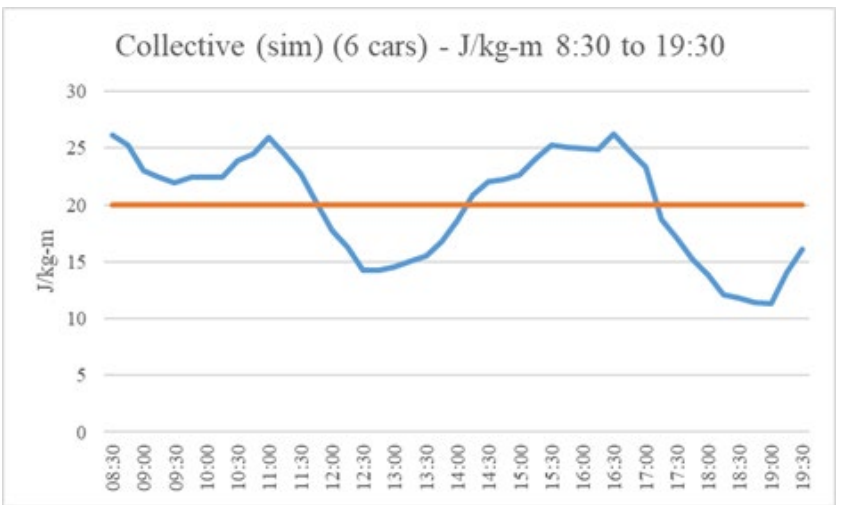

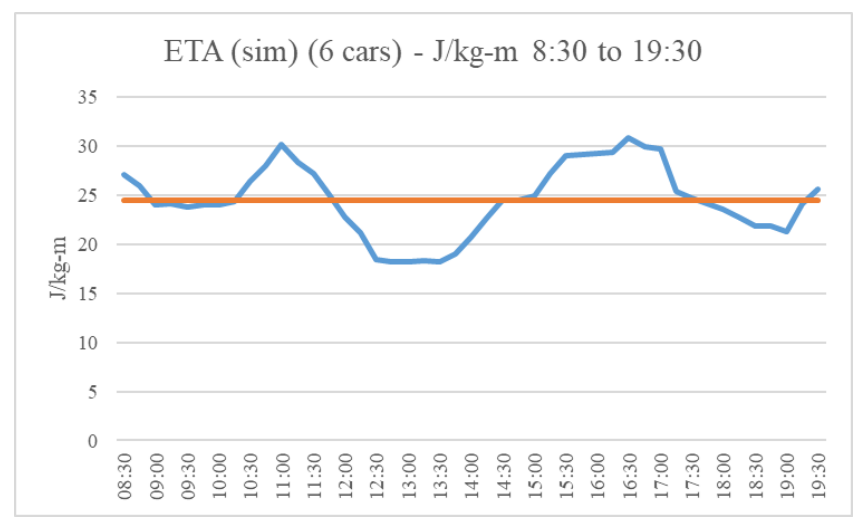

Figure $6(\mathrm{~b})<\mathrm{J} / \mathrm{kg}-\mathrm{m}>$ profile of six lifts based on real demand and simulated ETA

Figure $6(\mathrm{c})<\mathrm{J} / \mathrm{kg}-\mathrm{m}>$ profile of six lifts based on real demand and simulated Collective

The average value of Figure 6(a) throughout the whole day was $24.11 \mathrm{~J} / \mathrm{kg} / \mathrm{m}$, that of Figure $6(\mathrm{~b}$ ) was $24.53 \mathrm{~J} / \mathrm{kg} / \mathrm{m}$, and that of Figure 6(c) was $19.98 \mathrm{~J} / \mathrm{kg} / \mathrm{m}$. 


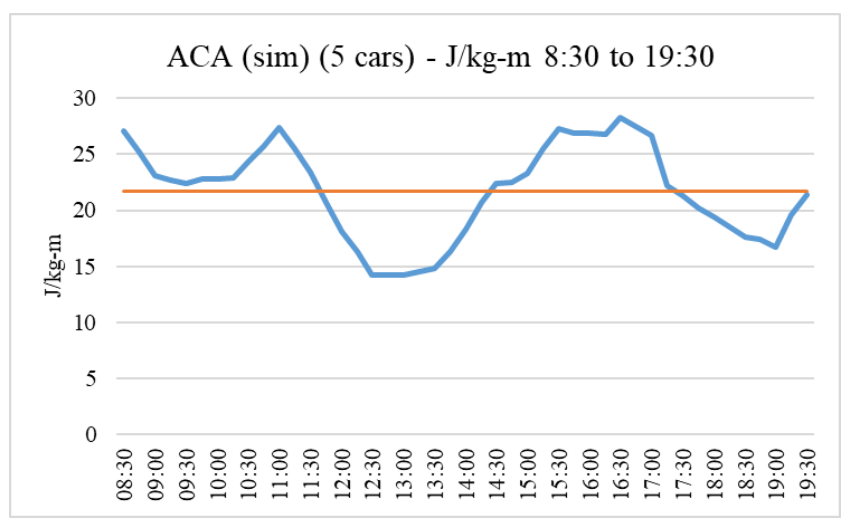

Figure $7(\mathrm{a})<\mathrm{J} / \mathrm{kg}-\mathrm{m}>$ profile of five lifts based on real demand and simulated ACA

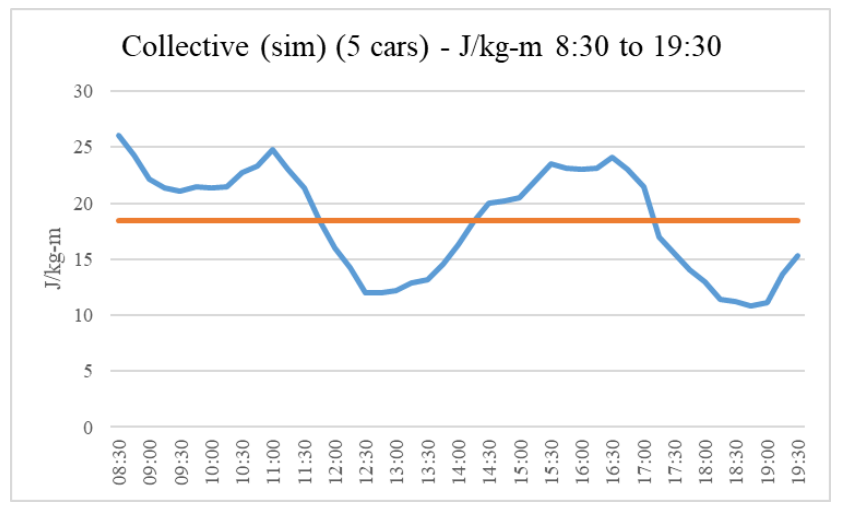

Figure $7(\mathrm{c})<\mathrm{J} / \mathrm{kg}-\mathrm{m}>$ profile of five lifts based on real demand and simulated Collective

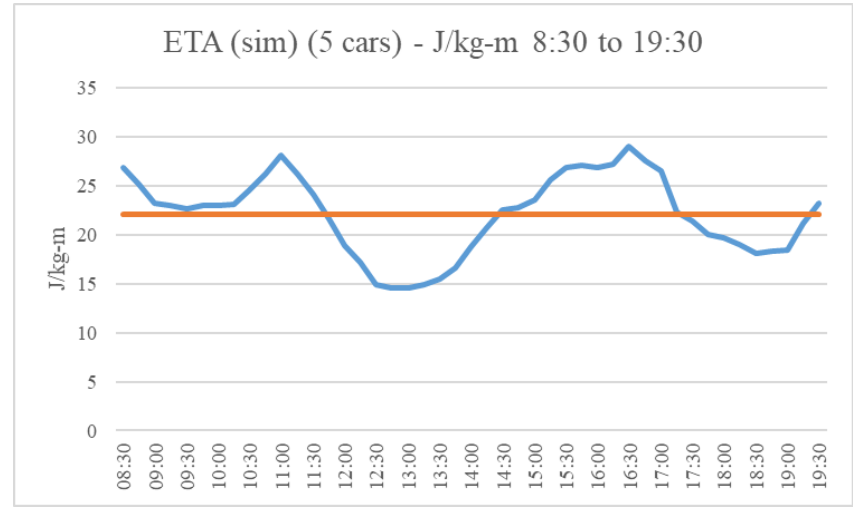

Figure $7(\mathrm{~b})<\mathrm{J} / \mathrm{kg}-\mathrm{m}>$ profile of five lifts based on real demand and simulated ETA

The average value of Figure 7(a) throughout the whole day was $21.69 \mathrm{~J} / \mathrm{kg} / \mathrm{m}$, that of Figure 7(b) was $22.11 \mathrm{~J} / \mathrm{kg} / \mathrm{m}$, and that of Figure 7(c) was $18.48 \mathrm{~J} / \mathrm{kg} / \mathrm{m}$.

The trend is rather obvious that the benchmarking parameter keeps on being reduced as the number of lifts is reduced while the passenger demand remains unchanged. In other words, the parameter is increased when the system is oversized as it is getting less efficient from an energy point of view. However, the designer should not only pay attention to the energy consumption. Another very important parameter in lift traffic performance is the average waiting time, $A W T$, which was also evaluated in every simulation by the software, as shown in Table 5 . 
Table 5 Average $<\mathrm{J} / \mathrm{kg}-\mathrm{m}>$ and $A W T$ versus Control Algorithms and Number of Lifts (by simulation)

\begin{tabular}{|c|c|c|c|c|c|c|}
\hline \multirow{2}{*}{$\begin{array}{c}\text { Number of } \\
\text { Lifts }\end{array}$} & \multicolumn{2}{|c|}{ ACA } & \multicolumn{2}{c|}{ ETA } & \multicolumn{2}{c|}{ Collective } \\
\cline { 2 - 7 } & $<$ J/kg-m> & $\boldsymbol{A W T}(\mathbf{s})$ & $<\mathbf{J} / \mathbf{k g}-\mathbf{m}>$ & $\boldsymbol{A W T} \mathbf{( s )}$ & $<\mathbf{J} / \mathbf{k g}-\mathbf{m}>$ & $\boldsymbol{A W T} \mathbf{( s )}$ \\
\hline \hline 7 & 25.58 & 11.8 & 25.81 & 11.0 & 20.67 & 13.0 \\
\hline 6 & 24.11 & 13.5 & 24.53 & 13.1 & 19.98 & 13.9 \\
\hline 5 & 21.69 & 17.9 & 22.11 & 17.6 & 18.48 & 16.4 \\
\hline
\end{tabular}

\subsection{Quick Analysis}

Contents in Table 5 make sense. As the number of lifts is reduced, the $A W T$ tends to increase as the system is gradually undersized. There are relatively less lifts to serve the same passenger demand and therefore passengers in general need to wait a bit longer to be served. But at the same time, the benchmarking parameter $<\mathrm{J} / \mathrm{kg}-\mathrm{m}>$ tends to decrease because lifts are more likely heavily loaded during most journeys. When the lifts are more heavily loaded journey by journey, the denominator of the $<\mathrm{J} / \mathrm{kg}-\mathrm{m}>$ expression tends to be higher with the same distance traveled and therefore the overall value tends to be smaller. Under Elevate ${ }^{\mathrm{TM}}$, the $20 \%$ spare capacity policy is not enforced.

It is reasonable to comprehend the three minima's by following the same approach as above. The $<\mathrm{J} / \mathrm{kg}-\mathrm{m}>$ value should be smallest during the down-peak and lunch-peak periods, depending on the characteristics of the traffic controller.

During down-peak, the lift car tends to move upward with light load from the ground floor to upper floors. That implies the whole journey is more or less operating under a re-generative braking mode because it is much heavier at the counterweight side which is traveling downward. When the lift car is fully loaded at the upper floors, it tends to express down to the ground floor under a heavy loaded condition. Again, that is mainly under a re-generative braking mode because it is much heavier at the car side which is again traveling downward.

During up-peak, the lift car tends to move upward from the ground floor heavily loaded where huge amount of energy is consumed. After the last passenger exits the lift car at the highest reversal floor, the car expresses down to the ground floor with very light load. During this express journey, the heavy counterweight is lifted upward and again, substantial energy has to be consumed. Fortunately, the number of passengers per 5-minute interval being served during an up-peak period is also the highest and a large denominator in the $<\mathrm{J} / \mathrm{kg}-\mathrm{m}>$ expression is expected. Hence, it is reasonable for a minima to exist but its value cannot be too low.

During lunch-peak, at the initial stage, the traffic looks like a down-peak as officers rush out of the building to grab lunch. Then, at the middle stage, a more or less balanced up- and down-traffic is expected as some officers leave the building while others return. At the final stage, the traffic should look like an up-peak situation as most officers return to their office after lunch. Therefore, it is reasonable to expect a minima during the lunch-peak with a value slightly less than that during the down-peak. The exact value very much depends on the real passenger demand and the performance of the traffic controller.

In between these three peaks, maxima's are expected because interfloor traffic mainly involves relatively low number of passengers in every journey and the distance traveled tends to be shorter, i.e. 
between floors close to one another that belong to the same company. Under this situation, energy has been consumed while the two elements at the denominator of $<\mathrm{J} / \mathrm{kg}-\mathrm{m}>$ are relatively small.

Talking about the different control algorithms, it seems that the ACA and ETA models cannot take advantage of the down-peak situation although they can still perform well during up-peak and lunchpeak periods. The reason may be due to the fact that during down-peak, lifts normally get fully loaded in much less number of stops at the upper floors. In other words, the passenger demand has already been automatically grouped together into minimum number of stops as all passengers more or less have the common destination, i.e. the ground floor. Under this situation, the intelligence of ACA and ETA cannot be fully utilized. Whereas, they may sometimes bring a hurdle to the overall traffic control because passengers have no free choice to take whatever lift is available.

Finally, the estimation in this study only includes the energy consumed when the lift car is moving, while ignoring the background energy which is still consumed when the lift car is stationary, such as that for lighting, ventilation, indication and control etc. Hence, the threshold value recommended should be a bit higher than that shown in Table 5 to be fair to all installations. That is the mark-up required.

\section{CONCLUSION}

The benchmarking parameter, $<\mathrm{J} / \mathrm{kg}-\mathrm{m}>$, was proposed more than fifteen years ago. Such parameter is applicable to lifts of different types (traction or hydraulic), brands and models because it is working on the fundamental physics of efficiency involving input and output. Furthermore, this parameter not only assesses the efficiency of the drive alone, but it also evaluates the performance of the dispatcher or the traffic controller. By grouping more passengers into lesser but longer trips, it is possible to lower the average value of the parameter.

When the parameter was first proposed, the recommended average value was $50 \mathrm{~J} / \mathrm{kg} / \mathrm{m}$ for a modern system of lifts. Two years ago (So et al 2018), by pure simulation with artificial passenger demand and an extremely simple energy model, a recommended average value of $40 \mathrm{~J} / \mathrm{kg} / \mathrm{m}$ was obtained for an efficient system. Readers are reminded that such a threshold value should only be applicable to a bank of lifts, the more lifts per bank the more desirable, controlled by a modern dispatcher. It should not be applied to a system with a single lift because there is basically no group control.

In this article, by using real passenger demand and real energy patterns, we are able to demonstrate that it is not impossible to achieve an average of $30 \mathrm{~J} / \mathrm{kg} / \mathrm{m}$ for a high quality and efficient system even when the background consumption is considered together. The average $<\mathrm{J} / \mathrm{kg}-\mathrm{m}>$ of the real system (real supervisory control, real traffic and real consumption) was found to be exceptionally high, i.e. worse, because the control was intentionally adjusted or tuned to take care of the comfort of those VIPs occupying the building. It is natural to believe that VIPs normally do not want to get crowded inside the car of limited space. Because of this strategy, the energy performance has to be sacrificed though the $A W T$ can still be maintained at an excellent value by oversizing the system.

Finally, in this study, the same energy pattern of the lift drive has been used while the control algorithms have been varied. The result shows that supervisory control can really affect the performance significantly by using this benchmarking parameter, in particular the value of the real system being doubled that of the simulated system. 
The authors would like to recommend the use of $40 \mathrm{~J} / \mathrm{kg} / \mathrm{m}$ as the threshold for the whole day average value of an energy efficient system while $30 \mathrm{~J} / \mathrm{kg} / \mathrm{m}$ may indicate an excellent one. This study further strengthens our previous recommendation by using real passenger and energy data, and explains the variation of the parameter throughout the whole working day with details of consideration. Of course, the criteria of measurement have to be specified and globally implemented for a fair comparison. A time window, $T=7,200$ seconds, is to be used with an incremental interval of $\Delta T=900$ seconds. The assessment period for an office building is suitably from 7:30 am to $8: 30 \mathrm{pm}$ on a weekday because the parameter can easily get unreasonably high during late evenings, midnights or on holidays as most lifts are under a standby model with a few passengers per hour. Such a high figure basically has no value of reference because the actual energy consumption is negligible.

One more point to be alert is the average waiting time and transit time of passengers. Energy saving is a desirable feature but not the key design issue; the highest priority of a lift system is to convey passengers around the built environment efficiently. Therefore, together with a benchmarking threshold of $<\mathrm{J} / \mathrm{kg}-\mathrm{m}>$, other benchmarking thresholds of $A W T$ and $A T T$ are needed, as mentioned before (So et al 2005).

\section{REFERENCES}

Buildings Department, Hong Kong (1995), Code of Practice for Overall Thermal Transfer Value in Buildings, http://www.bd.gov.hk/english/documents/code/OTTV-01.pdf.

EMSD (2012a), Code of Practice for Energy Efficiency of Building Services Installation, https://www.emsd.gov.hk/beeo/en/pee/BEC_2012 (Rev. 1).pdf.

EMSD (2012b), Technical Guidelines on Code of Practice for Energy Efficiency of Building Services Installation, https://www.emsd.gov.hk/beeo/en/pee/TG-BEC_2012 (Rev. 1).pdf.

EMSD (2015a), Code of Practice for Energy Efficiency of Building Services Installation, https://www.emsd.gov.hk/beeo/en/pee/BEC_2015.pdf.

EMSD (2015b), Technical Guidelines on Code of Practice for Energy Efficiency of Building Services Installation, https://www.emsd.gov.hk/beeo/en/pee/TG-BEC_2015.pdf.

EMSD (2018a), Code of Practice for Energy Efficiency of Building Services Installation, https://www.emsd.gov.hk/beeo/en/pee/BEC_2018.pdf.

EMSD (2018b), Technical Guidelines on Code of Practice for Energy Efficiency of Building Services Installation, https://www.emsd.gov.hk/beeo/en/pee/TG-BEC_2018.pdf.

Lam, Dante C.M., So, Albert T.P. and Ng T.K. (2006), "Energy conservation solutions for lifts and escalators of Hong Kong housing authority", Elevator Technology 16, Proceedings of 16th World Congress on Elevator Technologies, IAEE, Helsinki, June, pp. 190-199.

So A., Cheng G., Suen W. and Leung A. (2005), "Elevator performance evaluation in two numbers", Elevator World, Vol. LIII, No. 1, January, pp. 102-105.

So A. and Wong C.T.C. (2012), "Implementation of counterweight adjustment to achieve energy savings", Elevator Technology 19, Proc. Elevcon 2012, IAEE, Miami, May, 2012, pp. 185-192.

So A.T.P., Chan R. and Kaczmarczyk S. (2018), "Computer simulation aided study of a real-time energy benchmarking parameter for lift systems under different traffic control schemes", Transportation Systems in Buildings, Vol. 2, No. 1, http://dx.doi.org/10.14234/tsib.v2i1.

\section{BIOGRAPHICAL DETAILS}

Melvyn Ng is currently a student of MSc(Eng) in Energy Engineering in The University of Hong Kong and an Engineer in the Hong Kong lift and escalator industry. 
Ir Dr. Albert So is an executive board member and scientific advisor of the International Association of Elevator Engineers (IAEE). He is the honorary visiting professor of the University of Northampton in the U.K. He serves on the Advisory Group of Elevator World, Inc., and is based in Seattle. 